Contributors: ES, MR, and JW conceived and designed the study. ES conducted the epidemiological analyses. SB, HL, RH, and DB interpreted laboratory data. All authors critically reviewed and contributed to the final draft of the paper. MR is guarantor.

Funding: None.

Competing interests: DB's laboratory has received funding from vaccine manufacturers for specific projects. He has acted as an unpaid expert witness in MMR litigation for vaccine companies. All other authors have nothing to declare.

1 Gay NJ, Miller E, Hesketh L, Morgan-Capner P, Ramsay M, Cohen B, et al. Mumps surveillance in England and Wales supports introduction of two dose vaccination schedule. Commun Dis Rep CDR Rev 1997;7(2): R21-6.

2 Communicable Disease Surveillance Centre. Laboratory confirmed cases of measles, mumps and rubella, England and Wales: July to September 2002. Commun Dis Rep CDR Wkly 2002;12(48).

3 Gay NJ, Valambia S, Galasko D, Miller E. Selective rubella vaccination programmes: a survey of districts in England and Wales. Commun Dis Rep CDR Rev 1994;4(7):R77-9.

4 Communicable Disease Surveillance Centre. Fall in MMR vaccine coverage reported as further evidence of vaccine safety is published. Commun Dis Rep CDR Wkly 1999;9(26):227, 230.

5 Harling R, White JM, Ramsay ME, MacSween K, van den Bosch C. The effectiveness of the mumps component of the MMR vaccine: a case control study. Vaccine 2005 (in press).

(Accepted 14 April 2005)

\title{
MMR vaccine and Crohn's disease: ecological study of hospital admissions in England, 1991 to 2002
}

Valerie Seagroatt

See also p 1119, and Clinical review p 1132

Unit of Health-Care Epidemiology, Department of Public Health,

University of

Oxford, Oxford

OX3 7LF

Valerie Seagroatt

statistician

valerie.seagroatt@ dphpc.ox.ac.uk
It has been hypothesised that the measles, mumps, and rubella vaccine (MMR vaccine) increases the risk of autism and Crohn's disease. Although a possible link with autism has been extensively studied and refuted, ${ }^{1}$ a link with Crohn's disease has not. I tested this hypothesis by analysing trends in age specific admission rates for Crohn's disease in children and adolescents to determine if the introduction of MMR vaccine in 1988 increased rates in those populations that were offered the vaccine as infants.

\section{Methods and results}

Counts of admissions, taken as the first consultant episode in a hospital stay, in patients aged $\leq 18$ years with a main diagnosis of Crohn's disease in England (population 50 million) were available for the 12 years from April 1991 to March 2003. ${ }^{\mathrm{w} 1}$ I restricted the analysis to emergency admissions as these were probably less susceptible to changes in thresholds for admission and clinical practice than elective admissions. In the first two years of the MMR vaccination programme, the percentages of children completing a primary course of MMR vaccine in their second year of life were $7 \%$ and $68 \%$; thereafter the percentage was at least $84 \%$. ${ }^{2}$

Initially, temporal trends in age specific rates were plotted, differentiating between the rates for those born before and after the introduction of the vaccine. (Rates for patients aged 16 to 18 years-too old to have been offered the vaccine as infants-provided information on underlying trends unaffected by MMR vaccination in infancy.) Data for those born in 1987-8, of whom only $68 \%$ were vaccinated as infants, were excluded from the analysis. The MMR vaccination programme was then modelled as a variable with two levels (vaccination rate of $\geq 84 \%$ and of $\leq 7 \%$ ) using Poisson regression, with adjustment for year of admission and age in single years (as categorical variables).

There were 4463 admissions for Crohn's disease, 923 of which occurred in populations with a vaccination rate of $\geq 84 \%$ (those born in 1988-9 or later). Although the age specific rates increased over the study period, no obvious changes occurred that coincided with the intro-

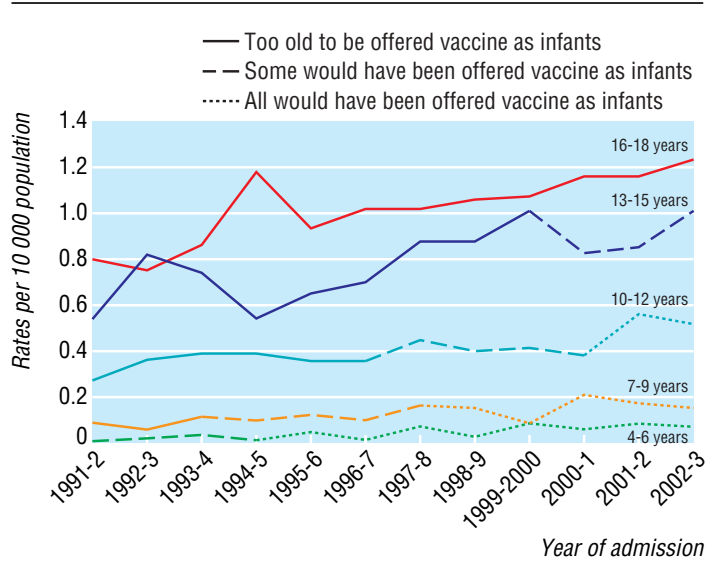

Age specific rates per 10000 population per year for emergency hospital admissions for Crohn's disease in England, 1991 to 2002. Rates in children aged $<4$ years were relatively low and so were excluded from the figure. Three-year groups, rather than the more conventional five-year groups, were used in order to discriminate between rates in children born before and after the introduction of MMR

duction of MMR vaccine (figure). The estimated rate ratio for the MMR vaccination programme (rates in populations with a vaccination rate of $\geq 84 \%$ compared with those with a rate of $\leq 7 \%$ ) was $0.95(95 \%$ confidence interval 0.84 to 1.08 )

\section{Comment}

The introduction of MMR vaccine, replacing the single measles vaccine, was not associated with an increase in Crohn's disease. Given the precision of the rate ratio, all but a small risk would have been detected. This was an ecological study, and findings from such studies generally need to be treated cautiously because of

Additional references (w1-w4) are on bmj.com

This article was posted on bmi.com on 18 April 2005: http://bmj.com/cgi/doi/10.1136/bmj.38449.476759.AE 


\section{What is already known on this topic}

It has been hypothesised that the measles, mumps, and rubella vaccine (MMR vaccine) increases the risk of Crohn's disease, though the evidence base for this hypothesis is sparse

\section{What this study adds}

An ecological analysis of national data on hospital admissions found no increase in Crohn's disease associated with the introduction of the MMR vaccination programme, providing strong evidence against the hypothesis that MMR vaccine increases the risk of Crohn's disease

potential for confounding. Could the negative finding from this analysis be due to confounding? If so, some factor(s) would have to be negatively associated with Crohn's disease, be introduced over the same three year period, and be targeted at the same population of infants as MMR vaccine to mask a true association. This seems highly unlikely.

A smaller ecological study ${ }^{2}$ and two case-control studies $^{3 \text { w3 }}$ also found no increased risk of Crohn's disease associated with MMR vaccine.

Initially, measles vaccine was reported to be associated with higher rates of Crohn's disease, ${ }^{4}$ but this was not confirmed by subsequent studies. ${ }^{35}$ Natural infections with measles and mumps within one year were also associated with an increased risk of Crohn's disease. $^{\mathrm{w} 4}$ Although that finding has yet to be confirmed, it raised the possibility that infections with multiple viruses in MMR vaccine might increase the risk of Crohn's disease. My study provides strong evidence against that hypothesis and adds to the evidence that MMR vaccine is no less safe in this respect than the single measles vaccine.

The Unit of Health-Care Epidemiology is funded by the National Co-ordinating Centre for Research Capacity Development at the Department of Health. I thank Steven Morgan at the South East Public Health Observatory for providing recent data from hospital episode statistics, and Paddy Farrington and Irene Stratton for comments on earlier versions of this manuscript. Contributors: VS is the sole contributor.

Funding: No special funding.

Competing interests: None declared.

Ethical approval: Not required.

1 Smeeth L, Cook C, Fombonne E, Heavey L, Rodrigues LC, Smith PG, et al. MMR vaccination and pervasive developmental disorders: a case-control study. Lancet 2004;364:963-9.

2 Pebody RG, Paunio M, Ruutu P. Measles, measles vaccination, and Crohn's disease. Crohn's disease has not increased in Finland. BMJ 1998;316:1745-6.

3 Davis RL, Kramarz P, Bohlke K, Benson P, Thompson RS, Mullooly J, et al. Measles-mumps-rubella and other measles-containing vaccines do not increase the ink for inllammatory bowel disease. a case-control study

4 Thompson NP, Montgomery SM, Pounder RE, Wakefield AJ. Is measles vaccination a risk factor for inflammatory bowel disease? Lancet 1995;345:1071-4.

5 Seagroatt V, Goldacre MJ. Crohn's disease, ulcerative colitis, and measles vaccine in an English population, 1979-1998. J Epidemiol Community Health 2003;57:883-7.

(Accepted 29 March 2005)

doi 10.1136/bmj.38449.476759.AE

\section{The gold standard: not a golden standard}

Studies that evaluate a new diagnostic test, procedure, or method should do so by comparing it with a time honoured alternative that is considered to be the current standard in the field. In this context the meaning of the word standard is "authoritative or recognised exemplar of quality or correctness." "Gold standard" is the popular term to describe this test; but "golden standard" is sometimes used as well. In fact, almost all medical publications in Dutch use the term "gouden standaard" which is a translation of "golden standard." Apparently, medical scientists have become confused about the true meaning of the term gold standard. Inspired by the Olympic Games, where the best athlete wins the gold medal, people who use "golden standard" think the term denotes the best standard in the world. Not bronze, not silver, but gold. Of course, this is incorrect.

Gold standard is a historical term borrowed from economists. It signifies a monetary standard, under which the basic unit of currency was defined by a stated quantity of gold. The analogy should be clear: the value of each country's method of payment (currency) was weighed against the gold standard, which made it possible to compare these different currencies for international trading.

In a Medline search from 1955 onwards, the first emergence of the term-albeit in a different meaning-was in 1962, in an anonymous commentary in the Lancet. Entitled "Towards a gold standard," it pleaded to set a standard for the use of gold salts in patients with rheumatoid arthritis. It may well have been Rudd who first introduced the "gold standard" in medicine in its current sense in $1979 .{ }^{1}$ In the following years, the number of publications that employed the term grew rapidly. This was much to the dismay of one biochemist, who thought the term was "presumptuous" for a biological test, since "the subject is in perpetual evolution [and] gold standards are by definition never reached."’ He proposed abolishing the term "because the phrase smacks of dogma ... After all, the financiers gave up on the idea of a gold standard decades ago." He failed in his mission, however: since 1995, over 10000 publications mentioned "gold standard."

So why is there also a "golden standard," a term used in over 600 publications since 1995 in English and in many more in foreign languages? I think this is because it is tempting to interpret the word "gold" in gold standard as an adjective, as in gold medal, and then to replace it with "golden," which simply sounds better if English is not your first language. In addition, "golden standard" is a persuasive term that makes sense: if a standard is the one test by which all others are judged, then the golden standard must be perfect.

Herein lies, I think, the importance of this discussion. The concept of a "golden standard" implies a level of perfection that can never be attained by any biological test, and will provoke criticism like that ventilated by Duggan. ${ }^{2}$ In contrast, a gold standard in its true meaning, derived from the monetary gold standard, merely denotes the best tool available at that time to compare different measures. Even in its glory days, the monetary gold standard was never considered perfect. It was subject to endless debate, and in the end it was abandoned for a better system. Similarly, today's gold standard tests will be replaced by better ones. As was eloquently stated by Versi: "It is the absolute truth that is never reached; gold standards are constantly challenged and superseded when appropriate."”

Jurgen A H R Claassen consultant geriatrician, Radboud University Nijmegen Medical Centre, Nijmegen, Netherlands (j.claassen@ger.umcn.nl)

Rudd P. In search of the gold standard for compliance measurement. Arch Intern Med 1979;139:627-8

2 Duggan PF. Time to abolish "gold standard" BMJ 1992;304:1568-9.

3 Versi E. "Gold standard" is an appropriate term. BMJ 1992;305:187. 